\title{
THE INVESTIGATION AND STUDY ON CURRENT TEA INDUSTRY DEVELOPMENT OF MENGLA COUNTY \\ Fei Li ${ }^{a}$, Xue Ding ${ }^{\text {b, }}$, Weifeng Wang ${ }^{\mathrm{c}}$ Yunnan Normal University Kunming, Yunnan, China alifei@ynnu.edu.cn, b1542143144@qq.com, '277924381@qq.com *Corresponding Author: Xue Ding
}

\begin{abstract}
Through the statistics on brand category of tea, tea enterprises and cooperatives, tea output value, per capita income of tea farmers in tea industry of Mengla County, and qualitative and quantitative analysis by use of Excel and CiteSpace software, this paper proposed the problems existing in the development of tea industry in southwest border mountain ethnic enclaves and countermeasures against problems, so as to promote the sustainable development of tea industry and the regional national economy.
\end{abstract}

Keywords: Tea industry; Industrial structure; brand construction

\section{Introduction}

Mengla County is one of the Xishuangbanna Dai autonomous prefecture in Ynnan province, it is located in the southwest border, neighboring with Laos and on the other side of the Lancang River with Myanmar. 70\% of the county's population of Mengla County is ethnic minorities, the main ethnic minorities are Dai, Hani, Yao and Yi. Mengla County has a long history in tea planting and processing. The famous " Yuanbao tea" and " Mansong tribute tea" is come from the north of Mengla County. Except "Youle tea mountain", another five ancient tea mountain, are all located in the Mengla County, including "Yibang tea mountain", "Manzhuan tea mountain" , " Gedeng tea mountain" , " Mansa tea mountain" and " Mangzhi tea mountain" . Mengla County is one of the universally accepted Pu'er tea origin where tea industry is the pillar industry, through which the farmers shake off poverty and achieve prosperity. Promoting the development of tea industry is significant in improving economic efficiency of the tea industry, increasing the income of residents in mountainous region, promoting the adjustment of agricultural industrial structure, then the economic and social development of Mengla County will be promoted.

\section{Data collection}

The data comes from the Yearbook of Mengla County and the CNKI. By logging in CNKI, and inputing "full-text = tea AND Mengla County " into the advanced searching box, we got 731 papers. By use of Excel and CiteSpace software, we analysis the brand category of tea, tea enterprises and cooperatives, tea output value, per capita income of tea farmers in tea industry of Mengla County.

\section{Present situation of tea industry}

From the results of Citespace analysis (Table 1), domestic research papers are mostly focused on " Six ancient tea mountain " , "old tea-trading route", "Ancient tea tree", "Pu'er tea", " Yiwu tea ", "Minority" etc, which reflects the emphasis of tea history culture in Mengla County. But the sustainable development of tea industry was ignored. As we all know that the prosperity of tea industry is beneficial to improving of the living standards of the minority, the unity and stability of the border areas. 
Table 1.Research hot spots statistical table

\begin{tabular}{|c|c|c|}
\hline Frequency & Year & Keyword \\
\hline 37 & 1981 & Six ancient tea mountain \\
\hline 18 & 2004 & Old tea-trading route \\
\hline 12 & 2004 & Pu'er Tea \\
\hline 11 & 1995 & Yunnan big-leaf tea \\
\hline 9 & 1984 & Yiwu tea \\
\hline 8 & 2001 & Minority \\
\hline 7 & 1995 & Growth of tea \\
\hline 6 & 1995 & Wild tea tree \\
\hline 6 & 1999 & Sustainable development \\
\hline 5 & 2000 & Tea culture \\
\hline 5 & 2000 & Ancient tea tree \\
\hline 5 & 2003 & Yunnan tea \\
\hline 5 & 2015 & Poverty alleviation work \\
\hline 4 & 1996 & Ethnic work \\
\hline 4 & 2006 & \\
\hline
\end{tabular}

\section{Data Analysis}

\subsection{Brand category of tea}

There are varieties of wild tea trees and so many brand categories of tea in Mengla County (Table 2), where the Pu'er tea is the well-known brand. Tea in Mengla County has many brands, such as: Yunnan Daye, Yunkang No.10, Foxiang tea, Changye pekoe, Snow bud No.100, Zijuan and Oolong etc. Each brands of tea has its own unique color and taste, but they are classified into Pu'er tea. People know little about other brands except Pu'er. Thus, tea brand construction in this area is still in its infancy.

Table 2.Distribution of every brand category of tea in Mengla County

\begin{tabular}{|c|c|c|c|c|c|c|c|}
\hline Types of tea & Daye & Yunkang No.10 & $\begin{array}{c}\text { Fuxiang } \\
\text { tea }\end{array}$ & $\begin{array}{c}\text { Changye } \\
\text { pekoe }\end{array}$ & $\begin{array}{c}\text { Snow bud } \\
\text { No.100 }\end{array}$ & Zijuan tea & Oolong tea \\
\hline $\begin{array}{c}\text { Planting } \\
\text { villages and } \\
\text { towns }\end{array}$ & $\begin{array}{l}\text { Yiwu town, } \\
\text { Xiangming } \\
\text { township, } \\
\text { Shangyong town, } \\
\text { Guanlei town, } \\
\text { Yaoqu township, } \\
\text { Menglun town, } \\
\text { Mengla town }\end{array}$ & $\begin{array}{l}\text { Yiwu town, } \\
\text { Xiangming } \\
\text { township, } \\
\text { Shangyong } \\
\text { town, } \\
\text { Guanlei town, } \\
\text { Mengban town, } \\
\text { Yaoqu township }\end{array}$ & $\begin{array}{l}\text { Yiwu } \\
\text { town, } \\
\text { Shangyong } \\
\text { town }\end{array}$ & $\begin{array}{l}\text { Yiwu } \\
\text { town, } \\
\text { Shangyong } \\
\text { town, } \\
\text { Mengban } \\
\text { town, } \\
\text { Yaoqu } \\
\text { township }\end{array}$ & $\begin{array}{l}\text { Shangyong } \\
\text { town, } \\
\text { Mengban } \\
\text { town, } \\
\text { Yaoqu } \\
\text { township }\end{array}$ & $\begin{array}{l}\text { Yiwu } \\
\text { town, } \\
\text { Xiangming } \\
\text { township, } \\
\text { Shangyong } \\
\text { town }\end{array}$ & $\begin{array}{l}\text { Yiwu } \\
\text { town, } \\
\text { Xiangming } \\
\text { township }\end{array}$ \\
\hline
\end{tabular}

\section{2}




\section{Tea enterprises and cooperatives}

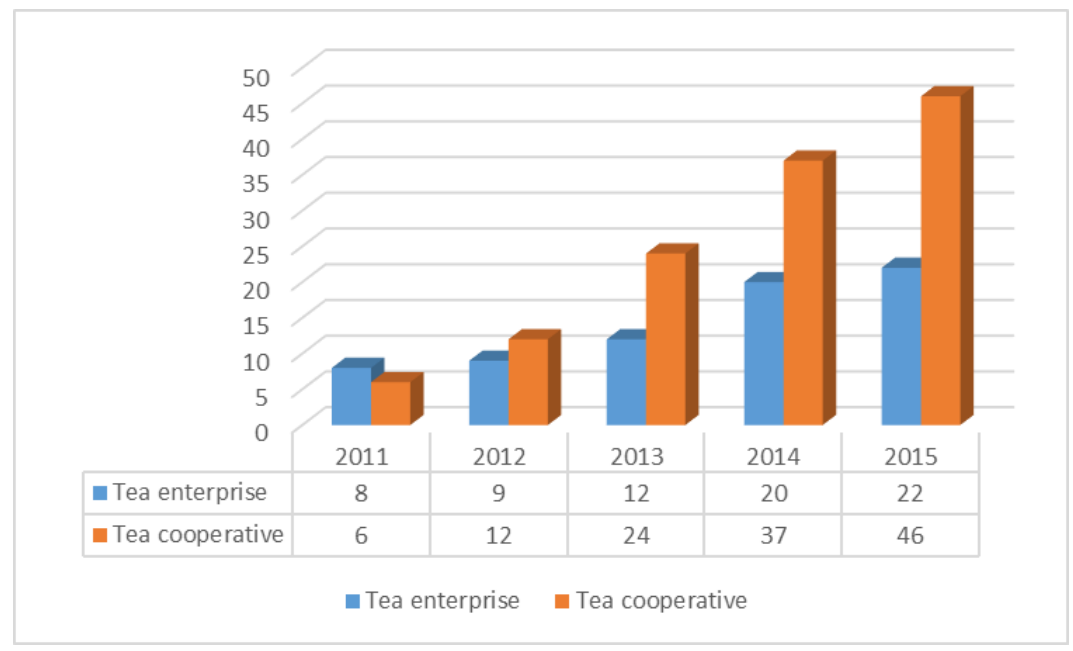

Fig 1. The number of tea enterprises and cooperatives in Mengla County

From tea enterprise statistical survey in 2015 by agriculture and technology bureau in Mengla County, there are only 21 hand-make tea enterprises and 1 advanced enterprise in tea processing. Each enterprise has very limited work place, manufacturing from raw material. Their products are mainly including seven loaves, bricks, Tuo tea, bamboo tea, melon tea, etc. From Figure 1, we can see the number of tea enterprises and cooperatives in Mengla County rising during the 12th Five-Year Plan period, especially in 2013 and 2014. The figure also indicated that the tea industry are developing in a good momentum. But the statistical survey reveals that the enterprises are mainly in a low hand-make level, less advanced enterprise. This phenomenon restricts the development of tea industry in Mengla County.

\subsection{Tea output value}

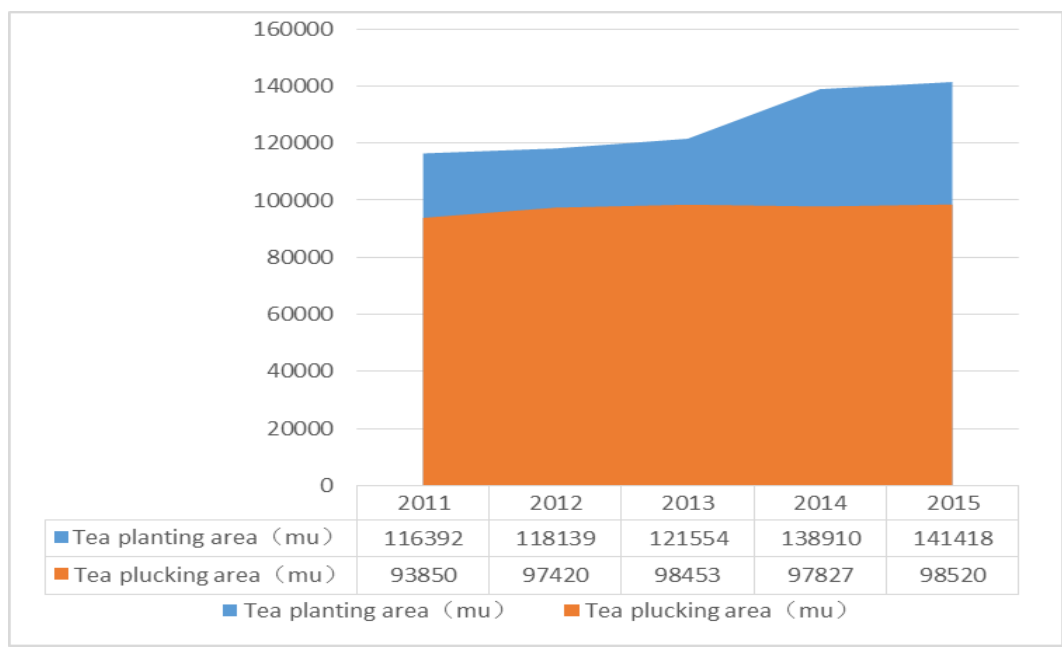

Fig 2. Nearly five years of tea planting and picking area statistics in Mengla County 


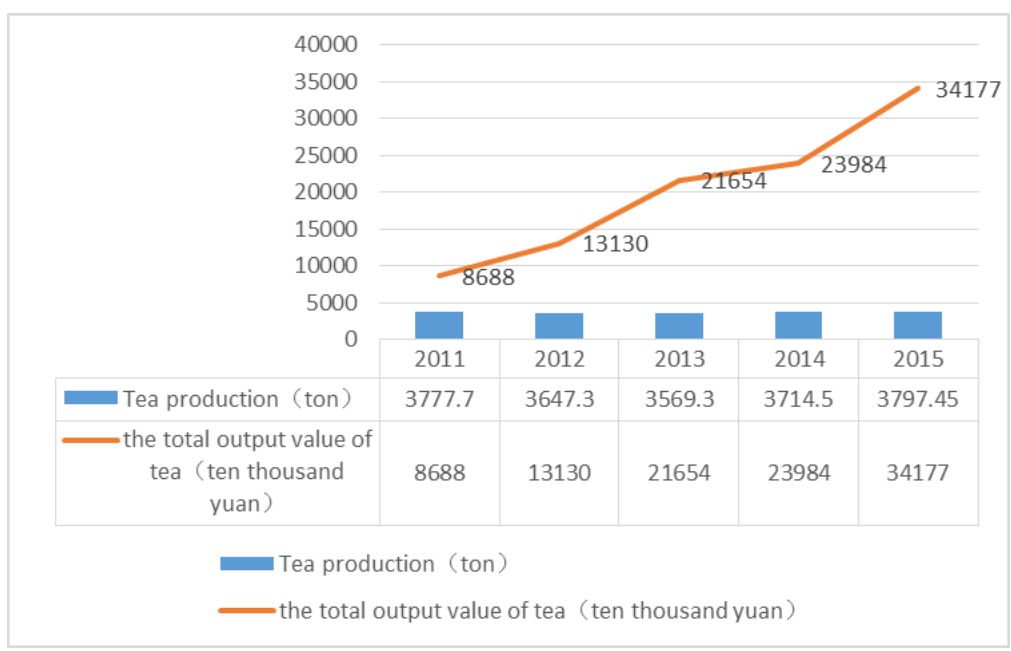

Fig 3. Tea output and total output value statistics of Mengla County nearly five years

Tea output value are based on tea growing area, picking area, production and price. From figure 2 and figure 3, tea growing area of Mengla County in nearly five years increased obviously, but the tea picking area of growth is not obvious. This indicates that tea garden development are lack of long-term planning and effective field management. But the tea output value in 2015 are increased almost four times the value in 2011, so promoting the tea industry in Mengla County is a good choice.

\subsection{Per capita income of tea farmers}

From table 3, the proportion of tea output value in agriculture began continuously to increase since 2011, from $2.59 \%$ in 2011 to $6.15 \%$ in 2015, which means the contribution of the tea output value was more and more in agricultural output value. At the same time, the tea income was one of the important income of residents. The per capita income of tea farmers increased from 4115 yuan in 2011 to 8209 yuan in 2015, increased 17.68\% annually. Tea industry plays a more important role in promoting rural economic development.

Tab 3.Output value of tea industry in Mengla County

\begin{tabular}{|c|c|c|c|c|c|}
\hline YEAR & $\mathbf{2 0 1 1}$ & $\mathbf{2 0 1 2}$ & $\mathbf{2 0 1 3}$ & $\mathbf{2 0 1 4}$ & $\mathbf{2 0 1 5}$ \\
\hline Tea output(10000 yuan) & 8688 & 13130 & 21654 & 23984 & 34177 \\
\hline Tea output growth rate & $26.67 \%$ & $51.13 \%$ & $64.92 \%$ & $10.76 \%$ & $42.50 \%$ \\
\hline $\begin{array}{c}\text { Agriculture total output } \\
\text { value(10000 yuan) }\end{array}$ & 335652 & 391035 & 489229 & 519478 & 555985 \\
\hline $\begin{array}{c}\text { The output value of tea } \\
\text { accounted for the proportion of } \\
\text { total output value of Agriculture }\end{array}$ & $2.59 \%$ & $3.36 \%$ & $4.43 \%$ & $4.62 \%$ & $6.15 \%$ \\
\hline $\begin{array}{c}\text { Per capita net income of } \\
\text { farmers (yuan) }\end{array}$ & 4115 & 5064 & 5891 & 7456 & 8209 \\
\hline $\begin{array}{c}\text { Farmers per capita net income } \\
\text { growth rate }\end{array}$ & $12.34 \%$ & $23.06 \%$ & $16.33 \%$ & $26.57 \%$ & $10.10 \%$ \\
\hline
\end{tabular}

\section{Conclusions and countermeasures}

Conclusion: The development of tea industry in Mengla County has made remarkable achievements, but some problems still exist, such as low production quality of raw materials, lack of brand construction, and lack of 
advanced processing, outdated processing facilities etc. At the same time, with the consumers demand for tea products is increasingly diverse, the international demand of quality and safety of tea products is getting higher and higher, more and more international technical trade barriers the export products faced, achieving the task that making Mengla tea industry bigger and stronger is very arduous.

Countermeasures: Firstly, the development of tea industry in Mengla County adhere to the combination of development and protection, developing and constructing "the green, ecological, environmental, high-quality tea" as the main direction, relying on the ancient tea and the ancient tea garden. To expand the planting area according to local conditions, we emphasis on increasing the investment in science and technology and improving the content of science and technology, to make the new tea garden realize the standardization, the high starting point, the good profits. Secondly, to create a set of standards for seed-breeding and the technical quality of tea picking, processing, packaging, storage, transportation and sales, we encourage and support tea enterprises to develop pollution-free tea, green food tea, organic tea base identification and product certification. Thirdly, to create a famous brand as the main line, to take the capital management as the carrier, we suggest Mengla integrate industry resources as the hitting-point, following the rules of market competition to enhance tea industry. Fourthly, on the tea industry talent shortage, the tea industry manager, tea craftsman and specialist should be hired and trained to help the tea enterprises solve the problem of shortage of senior personnel, to ensure the sustainable development of tea industry. Finally, the tea culture tourism should be actively promoted, using the Yiwu tourist town, the historic town, the Pu'er Tea and tribute tea Town, the Pu'er Tea Museum, the old tea-trading route, the ancient tea, the ancient tea plantation, to make the tourism drive the development of tea industry.

\section{Acknowledgments}

This paper is sponsored by Education Department of Yunnan as a scientific research subject (2016ZZX083).

\section{References}

1. The People's Government of Mengla County. The Yearbook of Mengla County. Yunnan: Dehong publishing house, 2014.

2. Li Fei, Zheng Minghui, Chen Yong, Li Jiamei. The present situation and outlet of the development of the tea industry in the south of Mengla County, Journal of the fortune times, 2015(11). 